\title{
MicroRNAs in Obesity, Metabolic Syndrome and Diabetes Mellitus
}

\author{
Anna Meiliana ${ }^{1,2 *}$ and Andi Wijaya ${ }^{1,2 *}$ \\ ${ }^{1}$ Post Graduate Program in Clinical Biochemistry, Hasanuddin University, Makassar \\ ${ }^{2}$ Prodia Clinical Laboratory, Jakarta \\ *Address correspondence to this author at: Prodia Clinical Laboratory, Jl. Cisangkuy No.2, Bandung \\ E-mail: anna_m@prodia.co.id, andi_w@prodia.co.id
}

\section{Abstract}

$\mathrm{B}$ ACKGROUND: MicroRNAs (miRNAs) are small regulatory RNAs that play important roles in development of diseases. Several studies have provided evidences showing that miRNAs affect pathways that are fundamental for metabolic control in adipocyte and skeletal muscle differentiations. Some miRNAs have been implicated in lipid, amino acid, and glucose homeostasis. This leads to the possibility that miRNAs may contribute to common metabolic diseases and point to novel therapeutic opportunities based on targeting of miRNAs.

CONTENT: miRNAs have been recognized as a class of epigenetic regulators of metabolism and energy homeostasis, primarily because the simultaneous regulation of a large number of target genes can be accomplished by a single miRNA. Emerging evidences suggest that miRNAs play a key role in the pathological development of obesity by affecting adipocyte differentiation. miRNAs have been implicated as novel protagonists in the pathogenesis of Diabetes Mellitus (DM), regulation of insulin production, secretion and action. They also appear to play a role in the development of diabetic complications such as nephropathy and cardiac hypertrophy.

SUMMARY: Involvement of miRNAs in glucose and lipid metabolism has provided strong evidences to confirm their roles as key players in regulation of complex metabolic pathways. Additionally, it indicates potential outlook for novel therapeutic strategies in the management of obesity, metabolic syndrome, and DM. Further research in this field is needed to ascertain the full potential of miRNAs as novel metabolic biomarkers and potent therapeutic agents against obesity and its metabolic disorders.

KEYWORDS: Obesity, Metabolic Syndrome, Diabetes, miRNAs, Adipogenesis, Insulin, Pancreatic- $\beta$-cells.

Indones Biomed J 2011 ; 3 (1) ; 4-17

\section{Introduction}

The 2006 Nobel Prize in Physiology or Medicine honored the discovery of RNA interference, in which scientists used short strands of the chemical to silence specific genes, and RNAi has helped shed light on the fact that cells naturally use RNA molecules of just 20 to 22 nucleotides long and dubbed miRNAs, to regulate gene expression (1).

MicroRNAs (miRNAs) are a family of 21-25nucleotide small RNAs that, at least for those few that have characterized targets, negatively regulate gene expression at the post-transcriptional level (2-4). The functions of miRNAs are not limited to the regulation of developmentally timed events. Instead, they have diverse expression patterns and probably regulate many aspects of development and physiology (2,3,5-7). Although the mechanisms through which miRNAs regulate their target genes are largely unknown, the finding that at least 
some miRNAs feed into the RNA interference (RNAi) pathway has provided a starting point in our journey to understanding the biological roles of miRNAs (8).

miRNAs may offer a window into the development of various ailments, including cancer, DM, and heart failure; and may provide a chance to strike disease targets that until now are unreachable (1).

The global efforts for miRNA cloning and characterization have led to establishment of an important collection of miRNA data. The miRNA registry contains up-to-date annotation for all published miRNAs (9). Most database entries require experimental validations of mature miRNA expressions and computational predictions of the corresponding hairpin precursors. MiRNAs have been shown to function in all organs directly related to the metabolism of glucose, namely, the pancreatic islet, liver, skeletal muscle, adipose tissue and brain (10). Interestingly, all tissues maintain a unique miRNA expression profile, perhaps suggesting that these sequences contribute to specific tissue functions by regulating a unique set of target genes.

Genome signature analysis has also been applied to study the involvement of miRNAs in lipid metabolism and cardiovascular disease. miRNAs are newly discovered regulators of gene expression, whose target genes and mechanism of action are the subject of extensive research. Investigation of these molecules and their genetic targets may potentially identify new pathways involved in complex metabolic disease processes, improving our understanding of metabolic disorders and influence future approaches to the treatment of obesity, metabolic syndrome, and DM (10).

\section{miRNA Biogenesis Mechanism and Functions}

miRNAs are a family of small, non-coding RNAs that regulate gene expression in a sequence-specific manner. The two founding members of the miRNA family were originally identified in Caenorhabditis elegans as genes that were required for timed-regulation of developmental events. Since then, hundreds of miRNAs have been identified in almost all metazoan genomes including worms, flies, plants and mammals (8). miRNAs have diverse expression patterns and might regulate various developmental and physiological processes. Their discovery has added a new dimension to our understanding of complex gene regulatory networks (8).
Almost coincident with the discovery of the second miRNA, let-7, small RNAs were also characterized as components of a seemingly separate biological process, RNAi. RNAi is an evolutionarily conserved, sequencespecific gene-silencing mechanism that is induced by exposure to double-stranded RNA (dsRNA) (11). In many systems, including worms, plants and flies, the stimulus that was used to initiate RNAi was the introduction of a dsRNA (the trigger) of $\sim 500 \mathrm{bp}$. The trigger is ultimately processed in vivo into small dsRNAs of $\sim 21-25$ bp in length, designated as small interfering RNAs (siRNAs) $(12,13)$. It is now clear that one strand of the siRNA duplex is selectively incorporated into an effector complex (the RNA-induced silencing complex; RISC). The RISC directs the cleavage of complementary mRNA targets, a process that is also known as post-transcriptional gene silencing (PTGS) (16). The evolutionarily conserved RNAi response to exogenous dsRNA might reflect an endogenous defense mechanism against virus infection or parasitic nucleic acids (11).

Fundamentally, siRNAs and miRNAs are similar in terms of their molecular characteristics, biogenesis and effector functions (8). miRNAs differ from siRNAs in their molecular origins and, in many of the cases that have been characterized so far, in their mode of target recognition. miRNAs are produced as a distinct species from a specific precursor that is encoded in the genome. The structure of the primary miRNA transcript and the recognition of this precursor by a nuclear processing machinery probably determines the sequence and structure of mature miRNAs. By contrast, siRNAs are sampled more randomly from long double-stranded (dsRNAs) that can be introduced exogenously or produced from bi-directionally transcribed endogenous RNAs that anneal to form dsRNA (11).

Two processing events lead to mature miRNA formation in animals. In the first event, the nascent miRNA transcripts (pri-miRNA) are processed into $\sim 70$ nucleotide precursors (pre-miRNA); in the second event that follows, this precursor is cleaved to generate $~ 21-25$ nucleotide mature miRNAs (14).

The sequential cleavages of miRNA maturation are catalysed by two RNase-III enzymes, Drosha and Dicer $(15,16)$. Both are dsRNA-specific endonucleases that generate 2-nucleotide-long $3^{\prime}$ overhangs at the cleavage site. Drosha is predominantly localized in nucleus and contains two tandem RNase-III domains, a dsRNAbinding domain and an amino-terminal segment of unknown function (15). Regardless of the diverse primary sequences and structures of pri-miRNAs, Drosha cleaves these into 70-bp pre-miRNAs that consist of an imperfect stemloop structure (15). 


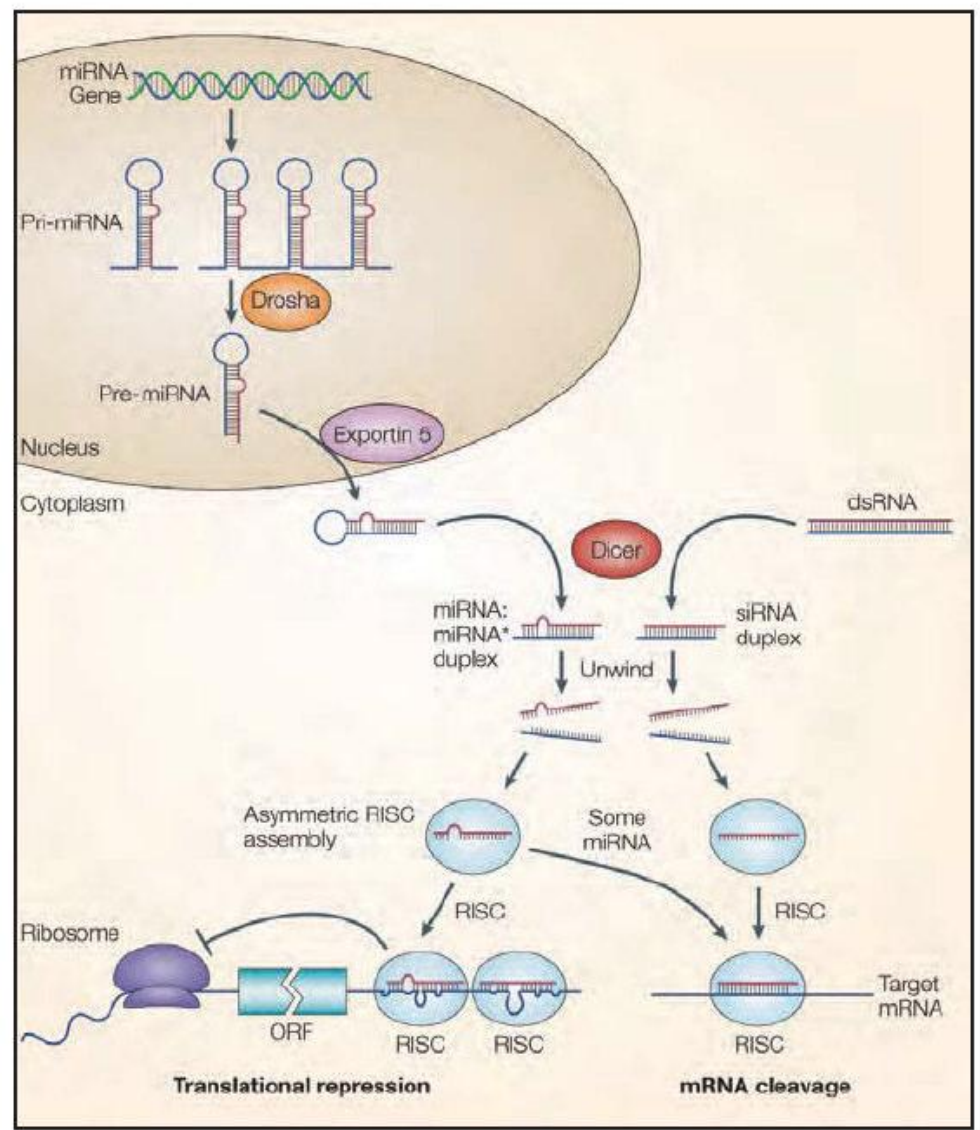

Figure 1. The current model for the biogenesis and post-transcriptional suppression of miRNAs and siRNAs (adapted with permission from Nature Publishing Group).

After the initial cleavage by Drosha, pre-miRNAs are exported from the nucleus into the cytoplasm by Exportin 5 (Exp5), a Ran-GTP dependent nucleo/cytoplasmic cargo transporter (17). Once inside the cytoplasm, these hairpin precursors are cleaved by Dicer into a small, imperfect dsRNA duplex (miRNA: miRNA*) that contains both the mature miRNA strand and its complementary strand (miRNA*) $(16,18,19)$. Dicer contains a putative helicase domain, a DUF283 domain, a PAZ (Piwi-ArgonauteZwille) domain, two tandem RNase-III domains and a dsRNA-binding domain (dsRBD) (20).

The effector complex for miRNAs shares core components with that of siRNAs, so that both are collectively referred to as the RNA-induced silencing complex (RISC). The target specificity, and probably also the functional efficiency of a miRNA requires that the mature miRNA strand from the miRNA:miRNA* duplex be selectively incorporated into the RISC for target recognition $(21,22)$.

Large-scale approaches for studying the regulatory effects of miRNAs have revealed important insights into target recognition and function. These approaches include computational analysis of selective maintenance or avoidance of miRNA complementary sites during evolution $(23,24)$ and experimental identification of messages destabilized or those preferentially associated with argonaute proteins in the presence of a miRNA (2532).

The impact of miRNAs on the proteome indicated that for most interactions of miRNAs act as rheostats to make fine-scale adjustments to protein output (33). Studies have shown that a single miRNA can directly downregulate production of hundreds of proteins. In addition to the known effect on global mRNA levels (26), data strongly indicate that miRNAs translationally repress hundreds of direct target genes (34). MiRNAs are involved in a plethora of important biological processes, from embryonic development to homeostasis in adult tissues. Recently, miRNAs have emerged as a class of epigenetic regulators of metabolism and energy homeostasis. 


\section{Circulating miRNA as Promising Novel Biomarkers}

Specific clinical biomarkers have potential to revolutionize diagnosis and treatment of various medical conditions, ranging from abnormal pregnancy to myocardial infarction and cancer. In particular, a theme of current cancer research is the quest for sensitive biomarkers that can be exploited to detect early neoplastic changes (36).

An ideal biomarker of tissue injury should be abundant, preferentially (or exclusively) produced in the tissue of interest, and typically present at low concentrations in the blood and other body fluids. Upon tissue injury, such biomarkers should be released into the systemic circulation or other body fluid, where they can be detected in a bloodbased assay or assay of other accessible body fluid.

miRNAs are endogenous, small noncoding RNAs. Because of their size, abundance, tissue specificity, and relative stability in plasma, miRNAs hold promise as unique accessible biomarkers to monitor tissue injury. miRNAs have been found to be involved in almost every biological process, from cellular differentiation and proliferation $(37,38)$ to cell death and apoptosis $(39,40)$, from synaptic plasticity (41) to immunity (42) and cardiovascular development (43). In addition, changes in miRNA levels and activity have been linked to human pathologies, including cancer (44) and cardiovascular diseases $(45,46)$.

The proof of concept study has revealed the potential of body fluid miRNAs to serve as practicable molecular markers for diverse physiological and pathological conditions, especially those where miRNAs have already been found to play a critical role, such as cancer (36). The ease of designing and optimizing an assay with such analyte specificity and of adapting it across species, makes miRNA assays a very attractive platform for the rapid deployment of improved safety biomarkers for drug development. Such a panel of diagnostic miRNAs could serve to detect induced toxicity in multiple tissues simultaneously.

\section{Therapeutic Strategy for Silencing} miRNA in Disease

Biologists who have made some of the early miRNA discoveries are eager to push toward new treatments for patients; hoping to also cash in, many are teaming up with biotechnology companies or establishing their own. Companies that formed several years ago to capitalize on different types of RNA molecules, notably ones used for RNAi or others known as antisense, are now expanding into the miRNA arena (1).

Two miRNA-based therapeutic strategies are being considered: delivering mimics of the molecules that could promote health or blunting the impact of ones that contribute to disease. As with any novel therapy, miRNAs come with their own set of challenges that must be overcome before testing begins in people.

miRNAs can regulate the mRNA levels of their targets $(26,47)$, and pharmacological silencing of miRNAs using antagomirs might therefore lead to the regulation of many mRNAs. A novel class of chemically engineered oligonucleotides, termed 'antagomirs', are efficient and specific silencers of endogenous miRNAs in mice. Intravenous administration of antagomirs against $m i R$ $16, m i R-122, m i R-192$ and $m i R-194$ resulted in a marked reduction of corresponding miRNA levels in liver, lung, kidney, heart, intestine, fat, skin, bone marrow, muscle, ovaries and adrenals. The silencing of endogenous miRNAs by this novel method is specific, efficient and long lasting. Studies have shown that antagomirs are powerful tools to silence specific miRNAs in vivo and may represent a therapeutic strategy for silencing miRNAs in disease (27).

miR-122 is a liver-expressed miRNA implicated in cholesterol and lipid metabolism and in hepatitis C virus (HCV) replication $(48,49)$, underscoring $m i R$ 122 as a potential therapeutic target for the treatment of hypercholesterolemia and hepatitis C infection. Elmén et al. show that the simple systemic delivery of an unconjugated, PBS-formulated locked-nucleic-acidmodified oligonucleotide (LNA-antimiR) effectively antagonizes the liver-expressed $m i R-122$ in non-human primates (50). Efficient silencing of $m i R-122$ was achieved in primates by three doses of $10 \mathrm{mg} / \mathrm{kg} \mathrm{LNA}$ antimiR, leading to a long-lasting and reversible decrease in total plasma cholesterol without any evidence for LNAassociated toxicities or histopathological changes in the study animals (50).

It has been shown that miRNAs are involved in cancer (51-54), cell growth and differentiation (55-57), insulin secretion (58) and viral infection (59); silencing of miRNAs with antagomirs or LNA-antimiR could become a therapeutic strategy for diseases (70) such as cancer, hepatitis and DM, and several others are almost certain to be discovered in which miRNAs participate in disease etiology. 


\section{miRNAs and Regulation of Glucose and Lipid Metabolism}

A role for miRNAs in energy metabolism was first suggested by a study in Drosophila melanogaster, illustrating a role for $m i R-14$ in fat metabolism (61). Maintaining appropriate blood glucose levels depends on the fine regulation of insulin release. Recently, heralded as 'ribo-regulators' of glucose homeostasis, miRNAs have proved to play a principal role in production and secretion of insulin, while simultaneously influencing sensitivity or resistance of its target tissues (62-64).

The pancreatic islet-specific $m i R-375$ plays a key role in blood glucose homeostasis through its regulation of beta cell function, particularly exocytosis of insulincontaining vesicles. Additionally, miR-124a and let-7b, both of which are also abundantly expressed in pancreatic islet cells are postulated to be important ribo-regulators of blood glucose (65).

Tang et al. have shown that miR-30d influences insulin transcription (66). Using the pancreatic beta-cell line MIN6, miR-30d was found to be up-regulated by increased cell exposure to higher glucose concentrations, and that higher miR-30d levels were associated with increased insulin gene expression. Conversely, inhibition of miR-30d was shown to rescind glucose-stimulated insulin gene transcription. Based on these results, it is suggested that the putative target genes of miR-30d may be negative regulators of insulin gene expression. Thus, emerging data lead us to believing that the powerful miRNA regulatory mechanism is intimately involved in glucose homeostasis.

A study into the role of $m i R-122$, a highly expressed liver miRNA, through antisense inhibition has shown that it plays an important role in cholesterol biosynthesis and triglyceride metabolism (67). The most striking effect of $m i R-122$ inhibition was lowering of plasma cholesterol and triglyceride levels.

miR-122 inhibition in normal mice resulted in reduced plasma cholesterol levels, increased hepatic fatty-acid oxidation, and a decrease in hepatic fatty-acid and cholesterol synthesis rates. Activation of the central metabolic sensor AMPK was also increased. miR-122 inhibition in a diet-induced obesity mouse model resulted in decreased plasma cholesterol levels and a significant improvement in liver steatosis, accompanied by reductions in several lipogenic genes. These results implicate $m i R-122$ as a key regulator of cholesterol and fatty-acid metabolism in the adult liver and suggest that miR-122 may be an attractive therapeutic target for metabolic disease (67).

Another recent study on the consequences of depleting $m i R-122$ corroborated its importance in cholesterol metabolism (27). The study also reported a significant decrease in plasma cholesterol levels. Gene expression analysis showed that the silencing of $m i R-122$ induced gene expression level variations of several hundred genes. The lower cholesterol level was attributed by the authors to the reduced level of 3-hydroxy-3-methylglutaryl coenzyme A reductase, the rate-limiting enzyme of the cholesterol biosynthesis pathway (68).

The authors of both papers suggested that the observed global reduction of the expression levels of lipogenic genes is probably caused by the fact that $m i R-122$ down regulates the expression of a hypothetical transcriptional repressor of these genes, suggesting another point of eventual therapeutic intervention (68).

Proper coordination of cholesterol biosynthesis and trafficking is essential to human health. The sterol regulatory element-binding proteins (SREBPs) are key transcription regulators of genes involved in cholesterol biosynthesis and uptake. Najafi-Shoustari et al. show that microRNAs $(m i R-33 a / b)$ embedded within introns of the SREBP genes target the adenosine triphosphate-binding cassette transporter A1 (ABCA1), an important regulator of high-density lipoprotein (HDL) synthesis and reverse cholesterol transport, for posttranscriptional repression. Antisense inhibition of $m i R-33$ in mouse and human cell lines causes up-regulation of ABCA1 expression and increased cholesterol efflux, and injection of mice on a western type diet with locked nucleic acid-antisense oligonucleotides resulted in elevated plasma highdensity lipoprotein (HDL) (69).

Vertebrates have two SREBP genes. SREBP-2 preferentially activates the synthesis and uptake of cholesterol, whereas $S R E B P-1$ preferentially activates the synthesis of fatty acids (70). Najafi-Shoushtari et al. and Rayner et al. reveal that both genes also encode, within their introns, a microRNA ( $m i R-33)$ that has the reciprocal effect. $m i R-33$ blocks the egress of cholesterol from cells by reducing the mRNA and protein levels for ABCA1, a transporter in the plasma membrane that secretes cholesterol from cells (71). When cells are depleted of cholesterol, both the transcription of SREBPS and the intron-encoded $m i R$ - 33 rise modestly.

ABCA1 functions most prominently in macrophages and hepatocytes (71). In macrophages, it excretes cholesterol that accumulates as a result of the uptake of oxidized cholesterol-carrying lipoproteins. In liver, ABCA1 is essential for the production of the precursor forms of HDL. Najafi-Shoushtari et al. and Rayner et al. 
show that delivery of a $m i R-33$ antagonist leads to a small but significant increase in plasma HDL.

In humans, insulin resistance is a hallmark of metabolic syndrome, which is provoked by obesity (72). In addition to hyperinsulinemia, hyperglycemia, and fatty liver, the cardinal features of metabolic syndrome include an increase in plasma triglyceride levels, owing to elevated very-low-density lipoproteins (VLDL), and a decrease in plasma HDL. Low HDL is believed to contribute to the increase of coronary heart disease in these subjects. Evidence suggests that the hypertriglyceridemia is caused by the insulin-induced increase in SREBP-1c mRNA and protein. Is it possible that the reduction in HDL is caused by a decrease in ABCA1, owing to the increased production of $m i R-33 b$ from the insulin-stimulated SREBP-1c gene? (73)

\section{Role of miRNAs in Obesity and Metabolic Syndrome}

Obesity and the metabolic syndrome are major public health concerns and present a formidable therapeutic challenge. The incidence of this disease spectrum continues to rise and contributes significantly to global morbidity, mortality and socioeconomic burden. Current treatment modalities include lifestyle modification, diet and pharmacologic agents; yet many patients remain recalcitrant to conventional medical therapy.

miRNAs play important regulatory roles in a variety of biological processes including adipocyte differentiation, metabolic integration, insulin resistance and appetite regulation (74) (Figure 2). Investigation of these tiny molecules and their genetic targets may potentially identify new pathways involved in complex metabolic disease processes, improving our understanding of metabolic disorders and influence future approaches to the treatment of obesity (10).

It is well acknowledged that abnormal and excessive fat accumulation in obese patients is associated with adverse health outcomes including an increased risk of life threatening diseases such as Type II DM, cardiovascular and cerebrovascular disease and malignancy (75). Crucial to the development of novel therapeutic strategies for obesity and its associated metabolic syndromes is better understanding of the regulation of adipogenesis.

Adipose tissue's functions are essential to energy metabolism because adipose tissue is not only an energy depot (76), but also a source of endocrine factors $(77,78)$.
Adipocytes are derived from mesenchymal stem or progenitor cells via a lineage-specific differentiation process called adipogenesis. Adipogenic differentiation is accomplished by a cascade of three major transcriptional events characterized by the transcriptional induction of: (a) the early genes CEBP $\gamma$ and CEBPS; (b) the determination genes PPAR $\gamma$ and CEBP $\alpha$, also regarded as master regulators of adipogenesis; and (c) adipocytespecific genes such as those encoding fatty acid synthase and fatty acid-binding proteins (79-81). Epigenetic regulation of adipose functions mediated by miRNAs has been emerging as an important mechanism in the study of energy metabolism and obesity (35).

Adipose tissue undergoes a dramatic expansion in obesity, which eventually results in adipose tissue dysfunction. Studies have shown that obese tissue becomes hypoxic or oxygen-deficient, and hypoxia facilitates inflammatory responses in adipocytes $(82,83)$. Studies have also shown that hypoxia strongly inhibits adipogenic differentiation $(84,85)$.

The $m i R-27$ gene family is down regulated during adipogenic differentiation. Overexpression of $m i R$ 27 specifically inhibited adipocyte formation, without affecting myogenic differentiation, and expression of $m i R-27$ resulted in blockade of expression of PPAR $\gamma$ and CEBP $\alpha$, the two master regulators of adipogenesis. Importantly, expression of $m i R-27$ was increased in fat tissue of obese mice and was regulated by hypoxia, an important extracellular stress associated with obesity. Those data strongly suggest that $m i R-27$ represents a new class of adipogenic inhibitors and may play a role in the pathological development of obesity (35).

Takanabe et al. observed miR-143 expression increased 3.3-fold in adipose tissue of obese mice, and they also report similarly altered levels of the adipocyte differentiation markers PPAR $\gamma$ and aP2 (86). Klöting et al. carried out the first miRNA expression profiling in human omental and subcutaneous adipose tissue and uncovered significant correlations between the expression of several fat depot specific miRNAs, adipose tissue morphology and key metabolic parameters such as BMI, lipid and hormone levels (87).

Wang et al.reported that the $m i R-17-92$ cluster was upregulated twofold during the early clonal expansion stage of adipogenesis and this family of miRNAs accelerated adipocyte differentiation by negatively regulating key cell cycle regulator and tumour suppressor gene Rb2/p130 (88). The inverse pattern of miRNA expression observed in differentiating adipocytes and obese tissue indicates that obesity leads to a loss of miRNAs that characterize fully differentiated and metabolically active adipocytes. 


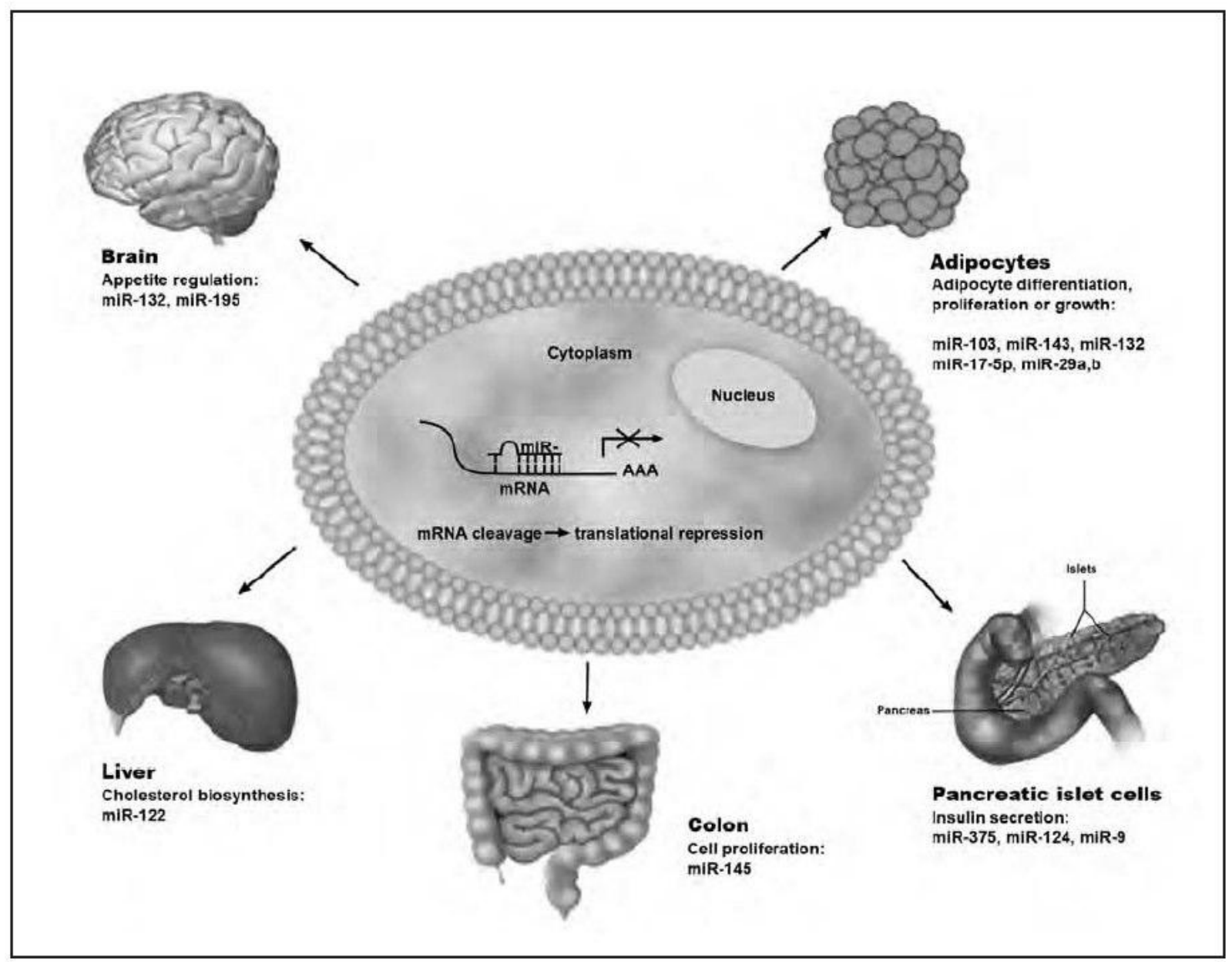

Figure 2. Known role of miRNAs in metabolically related issues: various miRNAs are specific to certain tissues important in metabolism such as the brain, liver, muscle, adipocyte and the pancreatic islet (Adapted with permission, Wiley \& Sons).

Xie et al. postulated that these changes were likely due to the chronic inflammatory environment in obese adipose tissue, which has been well described previously $(89,90)$. They concluded that these changes in miRNA expression observed in adipocytes were likely caused by the enhanced expression of TNF- $\alpha$ seen in obese fat tissue.

The brain and central and peripheral nervous systems have been implicated as key regulators of appetite, body fat content and glucose metabolism (91). miRNAs have recently been shown to be differentially expressed in brain tissue and have been linked to the regulation of neural factors specific to obesity, in particular the control of appetite, and in neural signalling to liver, muscle, pancreas and gastrointestinal tract, to influence metabolism. miR132 has been shown to be highly expressed in brain tissue and neuronal cell types, and evidence exists to show that $m i R-132$ is involved in the regulation of cAMP response element-binding protein (CREB) which is also known to function in glucose homeostasis (92).

Hypothalamic brain-derived neurotrophic factor (BDNF) is a key element in the regulation of energy balance and has been implicated in the development of obesity (93). This protein, encoded by the BDNF gene and secreted from the hypothalamus, is a member of the neurotrophin family of growth receptors and low expression levels have previously been linked to increased appetite and obesity (94). Both miR-30a-5p and miR-195 have been shown to target specific sequences surrounding the proximal polyadenylation site within the BDNF 3'untranslated region on chromosome 11p13. Furthermore, neuronal overexpression of $m i R-30 a-5 p$ and $m i R-195$, miRNAs enriched in layer III pyramidal neurons, resulted in down-regulation of BDNF protein. 


\section{Role of miRNAs in DM}

Maintaining appropriate blood glucose levels depends on the fine regulation of insulin release; when glucosestimulated insulin secretion fails, hyperglycemia ensues (95). Every step in the secretory pathway is tightly controlled at multiple levels, including the biosynthesis of insulin and secretory granule proteins, granule movement and exocytosis. Transcriptional regulation and the control of transcript stability and translational efficacy dictate the levels of insulin and other secretory granule proteins $(96,97)$.

Poy et al. originally identified several miRNAs which were differentially expressed in pancreatic endocrine cell lines. $m i R-375$ overexpression was found to reduce beta cell number and viability and thereby suppress glucosestimulated insulin secretion. Conversely functional experiments showed that miR-375 inhibition enhanced insulin secretion. These effects were shown to be mediated through miR-375's gene targets which include myotrophin (MTPN) and phosphoinositide-dependent kinase 1 (PDK1) $(60,98)$ and the results indicate that $m i R-375$ is a potentially important modulator of beta cell function.

Regulation of MTPN by $m i R-375$ may only be the tip of a large iceberg, as Jak2, ubiquitin-specific protease 1 and adiponectin receptor 2 are additional bona fide targets of $m i R-375$. Of note, $m i R-124$ and let-7b, that are also abundantly expressed in islet cells, coordinately repress MTPN, pointing to converging translational control of a single protein (65). Multiple targeting of a transcript may ensure sequential miRNA actions and fine-tuning of gene expression (99).

$m i R-9$ has been shown to regulate insulin release by decreasing expression of the transcription factor Onecut-2, that in turn promotes granuphilin/Slp4, a negative regulator of secretin (14). Baroukh and colleagues demonstrated that miR-124a preferentially targets Foxa2 - a master regulator of pancreatic development and of genes involved in glucose metabolism and insulin secretion (Kir6.2 and Sur-1). They concluded that this miRNA is an important regulator of a key transcriptional protein network in beta-cells and is responsible for modulating intracellular signaling.

miRNAs are not only involved in insulin production and secretion, but also control insulin signaling in target tissues of insulin action. Studies on miRNA expression in skeletal muscles of Goto-Kakizaki (GK) rats, a nonobese model of type $2 \mathrm{DM}$, identified two miR-29 family members including $m i R-29 a$ and $m i R-29 b$, but not $m i R$ $29 c$ to be upregulated in these diabetic animals compared to control animals (63). Further analysis using Northern blots revealed that members of the $m i R-29$ family were up regulated in all three insulin-responsive tissues, such as muscle, fat, and liver of diabetic rats.

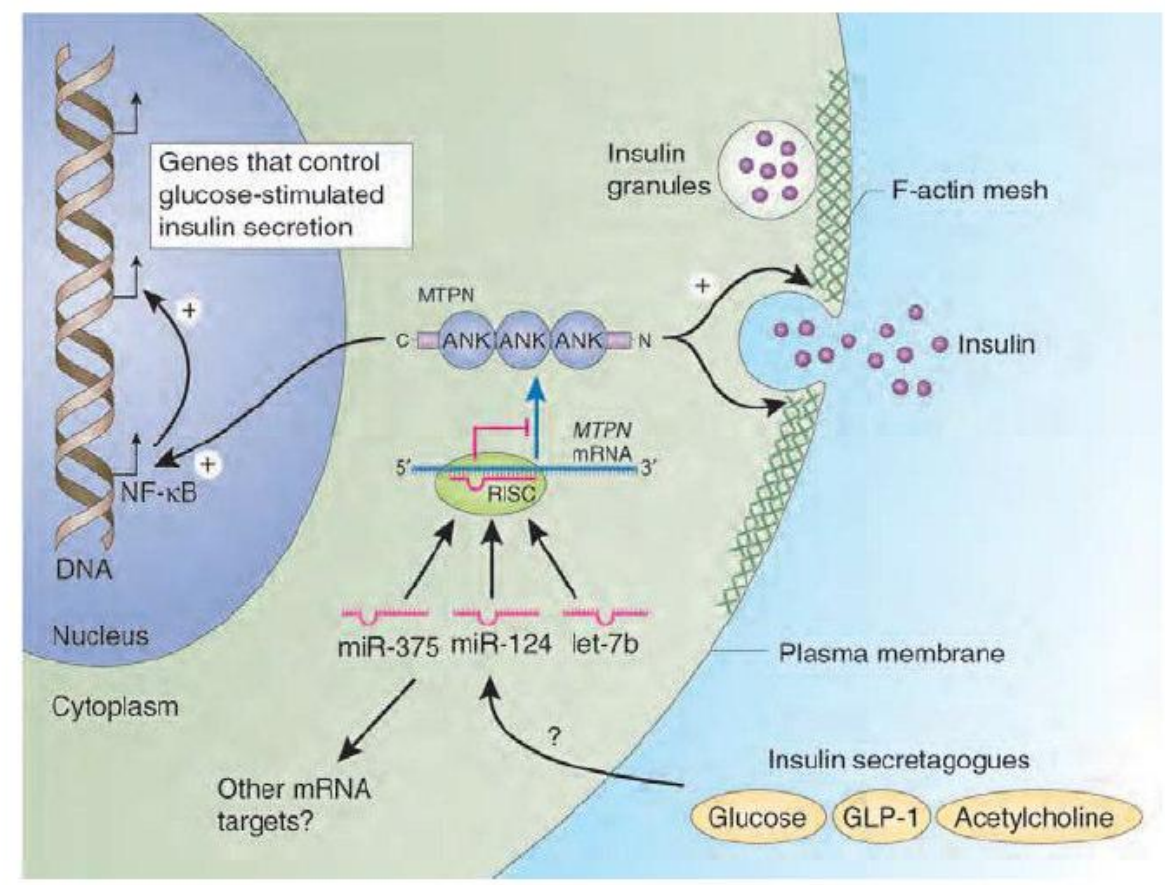

Figure 3. MicroRNA - mediated regulation of insulin exocytosis in the pancreatic beta cell (Adapted with permission from, Nature Publishing Group). 
Two candidate genes Insig1 (insulin-induced gene 1 ), an endoplasmic reticulum membrane protein that is involved in control of cholesterol biosynthesis and Cav2 (caveolin 2) have been validated as targets of $m i R-29 a / b / c$ using luciferase reporter assays and by Western blotting. Overexpression of $m i R-29$ caused a decrease in the levels of Insig 1 and Cav2 proteins (63).

$m i R-143$ has been shown to be up-regulated during adipocyte differentiation (100). Reduction of miR-143 by transfecting 2'-O-methoxyethyl phosphorothioatemodified antisense RNA oligonucleotides inhibited the expression of adipocyte-specific genes (insulin-sensitive glucose transporter/GLUT4), hormone sensitive lipase (HSL), fatty acid-binding protein, aP2 and peroxisome proliferator-activated receptor (PPAR-2), and the accumulation of triglycerides (1007). Interestingly, knockdown of miR-143 led to up regulation of one of the predicted targets, the mitogen-activated protein kinase ERK5/BMK1/MAPK7 suggesting that miR-143 may act through the target gene ERK5.

In Drosophila, miR-14 was found to regulate adipocyte droplet size and triacylglycerol levels (61) and $m i R-278$ appears to control insulin sensitivity in adipose tissue (101). In adipocytes, both IRS1 and IRS2 are expressed and have synergistic effects. Although IRS2 is central to the development of type $2 \mathrm{DM}$ and its associated complications, only IRS1 has recently been identified to be a target of miRNAs, specifically miR-145 (102).

Thus, recent data suggest that miRNAs play a direct role in insulin secretion (58), pancreatic islet development (103), beta cell differentiation (104), and indirectly control glucose and lipid metabolism (73) and are involved in secondary complications associated with DM $(105,106)$.

\section{Role of miRNAs as Diabetic Complication}

MiRNAs appear to also play a role in the establishment of DM complications. Data indicate that diabetic complications are often associated with changes in the levels of certain miRNAs in various tissues, including brain, heart, liver and kidney. The first miRNA that was shown to change its levels in diabetic hearts was miR-133. The changes of $m i R-133$ levels in heart are associated with two types of consequences: (1) a long QT syndrome (LQTS) (105) and (2) cardiac hypertrophy (107). LQTS is a life-threatening disorder that affects the heart's electrical system and may lead to fainting, cardiac arrest and possibly sudden death (108). Human ethera-go-go-related gene (HERG) was identified as a LQTS gene encoding a cardiac potassium channel responsible for rapid delayed rectifier $\mathrm{K}+$ current (IKr) (109). In diabetic hearts, the HERG protein was reduced by about $60 \%$ while the mRNA levels remained essentially unaltered $(105,110), m i R-133$ has been demonstrated to repress HERG expression and $m i R$ 133 expression levels itself appears to be regulated by the serum response factor SRF (105). While over-expression of $m i R-133$ induces LQTS, down regulation of $m i R-133$ levels lead to cardiac hypertrophy. In vitro over-expression of $m i R-133$ or miR-1 (both miRNAs come from the same transcriptional unit) inhibits cardiac hypertrophy.

miRNAs have been implicated in the epigenetic regulation of key metabolic, inflammatory, and antiangiogenic pathways in type $2 \mathrm{DM}$ and may contribute to common disease complications (111)s. Type 2 DM is one of the major risk factors of cardiovascular disease leading to endothelial dysfunction and micro and macro vascular complications $(112,113)$. miR-126 is highly enriched in endothelial cells and plays a pivotal role in maintaining endothelial homeostasis and vascular integrity (114). It facilitates vascular endothelial growth factor (VEGF) signaling by repressing 2 negative regulators of the VEGF pathway, including the Sprouty - related protein SPRED1 and phosphoinositol-3 kinase regulatory subunit 2 (PIK3R2.p85- $\beta$ ) (115). Plasma miRNAs are packaged in membranous vesicles that change in numbers, cellular origin, and composition depending on the disease state (116).

Shedding of $m i R-126$ from endothelial cells has been shown to regulate VEGF responsiveness and to confer vascular protection in a paracrine manner (117). Loss of $m i R-126$ was consistently associated with DM and the $m i R-126$ content in endothelial apoptotic bodies was reduced in a glucose-dependent fashion. Because apoptotic bodies and microparticles can be transferred to other cell types $(117,118)$, low plasma levels might result in reduced delivery of $m i R-126$ to monocytes and contribute to VEGF resistance and endothelial dysfunction.

Endothelial miR-126 are deregulated in patients with DM, which may ultimately lead to novel biomarkers for risk estimation and classification and could be exploited for miRNA-based therapeutic interventions of vascular complications associated with this disease (111).

Diabetic nephropathy (DN) and intercapillary glomerulonephritis are a progressive kidney disease that causes kidney failure in patients with longstanding DM. Of many genes that are involved in DN, one gene namely Smad-interacting protein 1 (SIP1) has recently been identified to be a target of $m i R-192$, a miRNA highly 
expressed in the kidney. It is suggested that transforming growth factor beta (TGF- $\beta$ ), SIP1, $\delta$-crystallin enhancer binding protein $(\delta \mathrm{EF} 1)$, collagen type I alpha 2 (Col1a2) and $m i R-192$ constitute a regulatory loop that is important in the control of kidney function. TGF- $\beta$ upregulates $m i R-192$ levels, which then causes downregulation of SIP1 through translational repression. TGF- $\beta$ also down regulates the transcription factor $\delta E F 1$, through unknown mechanisms. Consequently, down regulation of SIP1 and SEF1 collectively enhances the expression of Col1a2 by de-repressing the E-box elements located on the Col1a2 promoter. Up-regulation of TGF- $\beta$ or miR-192 was observed in glomeruli isolated from streptozotocininduced diabetic mice as well as diabetic $\mathrm{db} / \mathrm{db}$ mice compared to corresponding nondiabetic controls. These findings suggest a role for miR-192 in kidney and DN development (106).

\section{Therapeutic Potential of miRNAs in Obesity and DM}

The association between aberrant miRNA expression and abnormalities in glucose homeostasis, adipogenesis and obesity, and functional analysis of specific miRNAs illustrates the feasibility of using these molecules as targets for therapeutic intervention (119). Antagomirs (cholesterol conjugated anti-sense oligonucleotides) are pioneering targets for miRNAs silencing, as evidenced by hepatic miR-122 blockade in vivo (27). These preliminary data have prompted early clinical trials. Conversely, where miRNA expression is known to be under-expressed (e.g. $m i R-103$ in obese adipose tissue), induction of miRNA expression using viral or liposomal delivery of tissuespecific miRNAs to affected tissue could potentially result in restoration of catabolic activity to the tissue, although this concept of 'miRNA replacement therapy' has yet to be extrapolated in this setting (120).

Insulin, the hormone secreted by pancreatic $\beta$-cells, plays an essential role in the regulation of blood glucose levels and is a central factor in the control of body metabolism. Insulin release is finely tuned by changes in the concentrations of nutrients, other hormones and neurotransmitters allow a tight, moment-to-moment control of blood glucose levels. Secretion of amounts of insulin is insufficient to meet the metabolic demand resulting in chronic hyperglycemia and development of DM. Visceral obesity and elevated plasma free fatty acid (FFAs) concentrations are predisposing factors for the development of type 2 DM. Chronically elevated FFAs promote insulin resistance in target tissues and give detrimental effects on $\beta$-cells.

Alterations of miRNA activities are associated with numerous pathological conditions including cancer and neurological diseases (121). miRNA dysfunction can result from alterations in miRNA transcription/maturation leading to the expression of inappropriate levels of the miRNAs or from impairment in miRNA/target interactions (122).

Adipocyte differentiation and function can also be regulated by miRNAs. $m i R-143$ is upregulated during adipocyte differentiation and reduction of this miRNA results in decreased expression of adipocyte-specific genes and accumulation of triglycerides $(100,123)$. A recent report shows the presence of a second enriched miRNA in adipocytes, $m i R-103$. Overexpression of $m i R$ 103 also accelerates adipogenesis, as measured by the up regulation of many adipogenesis markers (89).

miRNAs also seem to be involved in DM-associated diseases. In fact, a variation in diabetic-associated expression of miRNAs has been detected in multiple organs, including heart and kidney. $m i R-1$ and $m i R-133$ are up regulated in rabbit diabetic heart tissue and ventricular samples from human diabetic patients $(105,124)$. Both TGF- $\beta$ and $m i R-192$ are upregulated in the renal glomeruli of type 1 and type 2 diabetic mice (106), suggesting that $m i R-192$ plays a role in the pathogenesis of diabetic nephropathy.

Because miRNA dysfunction is associated with the development of several diseases, including DM, these regulatory molecules represent attractive therapeutic targets. As described above, the mechanisms controlling miRNA biogenesis are now relatively well understood. Therefore, it could be envisaged to develop approaches to modulate miRNA maturation (122). Strategies permitting selective modulation of the expression or activity of one single miRNA would be much more attractive. miRNAs are small molecules with well-defined physicochemical properties. They can be easily synthesized and modified to improve their stability and facilitate their cellular delivery.

Depending on the role of the miRNA, the goal of the treatment will be to either increase or diminish miRNA function. To inhibit the function of miRNAs, several tools have been designed. The first and, for the moment, most widely used technique developed for this purpose relies on the ability of antisense nucleic acid derivatives to bind to the miRNA and prevent interaction with the targets. Stoffel et al. showed that modified derivates of these molecules, termed antagomirs, can also function in vivo (27). 
Systemically administered locked nucleic acid (LNA)antimiRs could also efficiently decrease the levels of $m i R$ 122 in the liver and consequently led to the upregulation of a large set of predicted target mRNAs (125). Morpholinos, another type of nucleotide derivatives, have been used to decrease miRNA expression in zebrafish (103). Morpholinos are synthetic uncharged P-chiral analogues of nucleic acids and have been shown to be effective, specific and lack non-antisense effects. Alternative strategies to inhibit miRNA function have been designed. One example is the use of 'miRNA sponges' (126). The principle of this approach consists of introducing in the cells a decoy mRNA containing multiple miRNA-binding sites in the 3' UTR and functioning as a competitive inhibitor for the targets.

DM and other disorders are often detected too late that leads to difficulties in diagnosis and treatments. Because many miRNAs are expressed in a tissue-specific manner and their levels in different organs vary in association with disease states, these small molecules represent an attractive new class of highly specific biomarkers $(54,127)$. miRNAs have been shown to be reasonably stable and, therefore, their level is well suited for being tested in patient samples. Moreover, Chen et al. have demonstrated that miRNAs can be detected in serum of different species and that their level is consistent among individuals of the same species (120).

A better knowledge of the properties and functions of these small regulators of gene expression may favor the design of novel therapeutic approaches for prevention and treatment of DM. This task will keep researchers busy for many years. However, if discoveries continue at the current extraordinary pace, we will soon know if miRNAs can hold all their promises and help the development of new tools for fighting DM, obesity, and its complications.

\section{Conclusion}

MiRNAs have emerged as an important class of posttranscriptional regulators of metabolism in several cell types, including $\beta$-cells, muscle cells, and adipocytes. They appear to be involved in diverse aspects of cellular responses to metabolic demands or stresses.

MiRNAs will also be useful as biomarkers for obesity, metabolic syndrome and DM. Furthermore, recent progress in the development and use of miRNA antagomiRs to target miRNAs in vivo may provide novel therapeutic tools for the treatment of obesity and DM and its complications in future.
Further studies are necessary to examine the efficacy and safety of these novel therapeutic approaches, and to explore the potential for circulating miRNAs to aid in the management of patients with obesity, metabolic syndrome, and DM; however, evidence to date is encouraging.

\section{References:}

1. Bouzin J. MicroRNAs make big impression in disease after disease. Science 2008; 319: 1782-4.

2. Ambros V. MicroRNA pathways in flies and worms: growth, death, fat, stress, and timing. Cell 2003; 113: 673-6.

3. Bartel DP. MicroRNAs : genomics, biogenesis, mechanism, and function. Cell 2004; 116: 281-97.

4. Lai EC. microRNAs : runts of the genome assert themselves. Curr Biol 2003; 13: R925-36.

5. McManus, M. T. MicroRNAs and cancer. Semin. Cancer Biol. 2003; 13: 253-258.

6. Carrington, J. C. \& Ambros, V. Role of microRNAs in plant and animal development. Science 2003; 301: 336-8.

7. Johnston, R. J. \& Hobert, O. A microRNA controlling left/right neuronal asymmetry in Caenorhabditis elegans. Nature 2003; 426: 845-9.

8. He L, Hannon GJ. MicroRNAs: small RNAs with a big role in gene regulation. Nat Rev Genet 2004; 5: 522-31.

9. Griffiths-Jones, S. The microRNA Registry. Nucleic Acids Res. 2004; 32: D109-D11.

10. Heneghan HM, Miller N, Kerin MJ. Role of microRNA in obesity and the metabolic syndrome. Obes Rev 2010; 11: 354 61.

11. Hannon, G. J. RNA interference. Nature 2002; 418: 244-251.

12. Elbashir SM, Harborth J, Lendecke W, Yalcin A, Weber K, Tusch T. Duplexes of 21-nucleotide RNAs mediate RNA interference in cultured mammalian cells. Nature 2001; 411 : 494-8.

13. Elbashir, S. M., Lendeckel, W. \& Tuschl, T. RNA interference is mediated by 21- and 22-nucleotide RNAs. Genes Dev. 2001; 15: 188-200.

14. Lee $\mathrm{Y}$, Jeon K, Lee JT, Kim S, Kim VN. MicroRNA maturation: stepwise processing and subcellular localization. EMBO J. 2002; 21: 4663-70.

15. Lee Y, Ahn C, Han J, Choi H, Kim J, Yim J, et al. The nuclear RNase III Drosha initiates microRNA processing. Nature 2003; 425: 415-9.

16. Hutvágner G, McLachlan J, Pasquinelli AE, Bálint E, Tuschl T, Zamore PD. A cellular function for the RNAinterference enzyme Dicer in the maturation of the let-7 small temporal RNA. Science 2001; 293: 834-8.

17. Lund, E, Guttinger S, Calado A, Dahlberg JE, Kutay U. Nuclear export of microRNA precursors. Science 2004; 303: 95-8.

18. Grishok A, Pasquinelli AE, Conte D, Li N, Parrish S, Ha I, et al. Genes and mechanisms related to RNA interference regulate expression of the small temporal RNAs that control C. elegans developmental timing. Cell 2001; 106: 23-34.

19. Ketting RF, Fischer SE, Bernstein E, Sijen T, Hannon GJ, Plasterk RH. Dicer functions in RNA interference and in synthesis of small RNA involved in developmental timing in C. elegans. Genes Dev. 2001; 15: 2654-9.

20. Bernstein E, Caudy AA, Hammond SM, Hannon GJ. Role for a bidentate ribonuclease in the initiation step of RNA interference. Nature 2001; 409: 363-6. 
21. Schwarz DS, Hutvágner G, Du T, Xu Z, Aronin N, Zamore PD. Asymmetry in the assembly of the RNAi enzyme complex. Cell 2003; 115: 199-208.

22. Khvorova A, Reynolds A, Jayasena SD. Functionalsi RNAs and miRNAs exhibit strand bias. Cell 2003; 115: 209-16.

23. Lewis BP, Shih IH, Jones-Rhoades MW, Bartel DP, Burge CB. Prediction of mammalian microRNA targets. Cell 2003; 115 : 787-98.

24. Nielsen CB, Shomron N, Sandberg R, Hornstein E, Kitzman J, Burge CB. Determinants of targeting by endogenous and exogenous microRNAs and siRNAs. RNA 2007; 13: 1894 1910.

25. Grimson A, Farh KK, Johnston WK, Garrett-Engele P, Lim LP, Bartel DP. MicroRNA targeting specificity in mammals: determinants beyond seed pairing. Mol. Cell 2007; 27: 91 105.

26. Lim LP, Lau NC, Garrett-Engele P, Grimson A, Schelter JM, Castle $\mathrm{J}$, et al. Microarray analysis shows that some microRNAs downregulate large numbers of target mRNAs. Nature 2005; 433: 769-73.

27. Krützfeldt J, Rajewsky N, Braich R, Rajeev KG, Tuschl T, Manoharan $\mathrm{M}$, et al. Silencing of microRNAs in vivo with 'antagomirs'. Nature 2005; 438: 685-9.

28. Giraldez AJ, Mishima Y, Rihel J, Grocock RJ, Van Dongen S, Inoue $\mathrm{K}$ et al. Zebrafish MiR-430 promotes deadenylation and clearance of maternal mRNAs. Science 2006; 312 : 75-9.

29. Beitzinger M, Peters L, Zhu JY, Kremmer E, Meister G. Identification of human microRNA targets from isolated argonaute protein complexes. RNA Biol 2007; 4 :7 6-84.

30. Easow G, Teleman AA, Cohen SM. Isolation of microRNA targets by miRNP immunopurification. RNA 2007; 13 : 1198-204.

31. Karginov FV, Conaco C, Xuan Z, Schmidt BH, Parker JS, Mandel $\mathrm{G}$, et al. A biochemical approach to identifying microRNA targets. Proc. Natl Acad. Sci. USA 2007; 104 : 19291-6.

32. Zhang L, Ding L, Cheung TH, Dong MQ, Chen J, Sewell AK, et al. Systematic identification of $C$. elegans miRISC proteins, miRNAs, and mRNA targets by their interactions with GW182 proteins AIN-1 and AIN-2. Mol. Cell 2007; 28: 598-613.

33. Baek D, Villén J, Shin C, Camargo FD, Gygi SP, Bartel DP. The impact of microRNAs on protein output. Nature $2008 ; 455$ : 64-71.

34. Selbach M, Schwanhäusser B, Thierfelder N, Fang Z, Khanin $\mathrm{R}$, Rajewsky N. Widespread changes in protein synthesis induced by microRNAs. Nature 2008; 455: $58-63$.

35. Lin Q, Gao Z, Alarcon RM, Ye J, Yun Z. A role of mir-27 in the regulation of adipogenesis. Febs J 2008; 276: 2348-58.

36. Gilad S, Meiri E, Yogev Y, Benjamin S, Lebanony D, Yerushalmi $\mathrm{N}$, et al. Serum microRNAs are promising novel biomarkers. Plos One 2008; 3: e3148.

37. Carleton M, Cleary MA, Linsley PS. MicroRNAs and cell cycle regulation. Cell Cycle. 2007; 6: 2127-32.

38. Bueno MJ, de Castro IP, Malumbres M. Control of cell proliferation pathways by microRNAs. Cell Cycle. 2008; 7: 3143-8.

39. Schickel R, Boyerinas B, Park SM, Peter ME. MicroRNAs: key players in the immune system, differentiation, tumorigenesis and cell death. Oncogene. 2008; 27: 5959-74.

40. Jovanovic M, Hengartner MO. miRNAs and apoptosis: RNAs to die for. Oncogene. 2006; 25: 6176-87.

41. Schratt G. microRNAs at the synapse. Nat Rev Neurosci. 2009; 10: $842-9$.

42. Xiao C, Rajewsky K. MicroRNA control in the immune system: basic principles. Cell. 2009; 136: 26-36.

43. Liu N, Olson EN. MicroRNA regulatory networks in cardiovascular development. Dev Cell. 2010; 18: 510-25.

44. Garzon R, Calin GA, Croce CM. MicroRNAs in cancer. Annu
Rev Med. 2009; 60: 167-79.

45. Small EM, Frost RJ, Olson EN. MicroRNAs add a new dimension to cardiovascular disease. Circulation. 2010; 121: 10221032.

46. Latronico MV, Condorelli G. MicroRNAs and cardiac pathology. Nat Rev Cardiol. 2009; 6: 419-29.

47. Bagga S, Bracht J, Hunter S, et al. Regulation by let-7 and lin-4 miRNAs results in target mRNA degradation. Cell 2005; 122: 553-63.

48. Jopling $C L, Y i M$, Lancaster $A M$, Lemon SM, Sarnow $P$. Modulation of hepatitis $C$ virus RNA abundance by a liverspecific microRNA. Science 2005; 309: 1577-81.

49. Randall G, Panis M, Cooper JD, Tellinghuisen TL, Sukhodolets $\mathrm{KE}$, Pfeffer S, et al. Cellular cofactors affecting hepatitis C virus infection and replication. Proc. Natl Acad. Sci. USA 2007; 104: 12884-9.

50. Elmén J, Lindow $M$, Schütz $S$, Lawrence $M$, Petri $A$, Obad $S$, et al. LNA - mediated microRNA silencing in non - human primates. Nature 2008; 452: 896-900.

51. Eis PS, Tam W, Sun L, Chadburn A, Li Z, Gomez MF, et al. Accumulation of miR-155 and BIC RNA in human B cell lymphomas. Proc. Natl Acad. Sci. USA 2005; 102: 362732.

52. Metzler M, Wilda M, Busch K, Viehmann S, Borkhardt A. High expression of precursor microRNA-155/BIC RNA in children with Burkitt lymphoma. Genes Chromosom. Cancer 2004; 39: 167-9.

53. He L, Thomson JM, Hemann MT, Hernando-Monge E, Mu D, Goodson S, et al. A microRNA polycistron as a potential human oncogene. Nature 2005; 435: 828-33.

54. Lu J, Getz G, Miska EA, Alvarez-Saavedra E, Lamb J, Peck D, et al. MicroRNAexpression profiles classify human cancers. Nature 2005; 435: 834-8.

55. Zhao $Y$, Samal E, Srivastava D. Serum response factor regulates a musclespecific microRNA that targets Hand2 during cardiogenesis. Nature 2005; 436: 214-20.

56. Chen CZ, Lodish HF. MicroRNAs as regulators of mammalian hematopoiesis. Semin. Immunol. 2005; 17: 155-65.

57. Cheng AM, Byrom MW, Shelton J, Ford LP. Antisense inhibition of human miRNAs and indications for an involvement of miRNA in cell growth and apoptosis. Nucleic Acids Res. 2005; 33: 1290-7.

58. Poy MN, Eliasson L, Krutzfeldt J, Kuwajima S, Ma X, Macdonald $\mathrm{PE}$, et al. Pancreatic islet-specific microRNA regulates insulin secretion. Nature 2004; 432: 226-30.

59. Jopling $C L, Y i M$, Lancaster $A M$, Lemon SM, Sarnow $P$. Modulation of hepatitis C virus RNA abundance by a liverspecific microRNA. Science 2005; 309: 1577-80.

60. Weiler J, Hunziker J, Hall J. Anti-miRNA oligonucleotides (AMOs): ammunition to target miRNAs implicated in human disease? Gene Therapy 2006; 13: 496-502.

61. Xu P, Vernooy SY, Guo M, Hay BA. The Drosophila microRNA Mir-14 suppresses cell death and is required for normal fat metabolism. Curr Biol 2003; 13: 790-5.

62. Gauthier BR, Wollheim CB. MicroRNAs: 'ribo-regulators' of glucose homeostasis. Nat Med 2006; 12: 36-38.

63. He A, Zhu L, Gupta N, Chang Y, Fang F. Overexpression of micro ribonucleic acid 29 , highly up-regulated in diabetic rats, leads to insulin resistance in 3T3-L1 adipocytes. Mol Endocrinol 2007; 21: 2785-94.

64. Poy MN, Spranger M, Stoffel M. MicroRNas and the regulation of glucose and lipid metabolism. Diabetes Obes Metab 2007; 9: 67-73.

65. KrekA, Grün D, Poy MN, Wolf R, Rosenberg L, Epstein EJ, et al. Combinatorial microRNA target predictions. Nature Genet 2005; 37: 495-500.

66. Tang X, Muniappan L, Tang G, Ozcan S. Identification of glucose- 
regulated miRNAs from pancreatic \{beta\} cells reveals a role for miR-30d in insulin transcription. RNA 2009; 15: 287-93

67. Esau C, Davis S, Murray SF, Yu XX, Pandey SK, Pear M, et al. miR-122 regulation of lipid metabolism revealed by in vivo antisense targeting. Cell Metab 2006; 3: 87-98.

68. Baralle M, Baralle FE. Genetics and molecular biology: micro RNAs are welcome to the lipid field. Curr Opin Lipidol 2007; 18: $375-7$

69. Najafi-Shoushtari SH, Kristo F, Li Y, Shioda T, Cohen DE, Gerszten RE, et al. MicroRNA-33 and the SREBP host genes cooperate to control cholesterol homeostasis. Science 2010; 328: 1566-73.

70. Horton JD, Goldstein JL, Brown MS. SREBPS: activators of the complete program of cholesterol and fatty acid synthesis in the liver. J Clin Invest. 2002; 109: 1125-31.

71. Attie AD. ABCA1: at the nexus of cholesterol, $\mathrm{HDL}$ and atherosclerosis. Trends Biochem Sci. 2007 ; 32: 172-9.

72. Reaven GM. Why Syndrome X? From Harold Himsworth to the insulin resistance syndrome. Cell Metab. 2005; 1: 9-14.

73. Brown MS, Ye J, Goldstein JL. HDL miR=ed down by SREBP introns. Science 2010; 328: 1495-6.

74. Krützfeldt J, Stoffel M. MicroRNAs: a new class of regulatory genes affecting metabolism. Cell Metab 2006; 4: 9-12.

75. Kopelman P. Obesity as a medical problem. Nature 2000; 404: 635-43.

76. Klaus $\mathrm{S}$. Adipose tissue as a regulator of energy balance. Curr Drug Targets 2004; 5: 241-50.

77. Qatanani M, Lazar MA. Mechanisms of obesity-associated insulin resistance: many choices on the menu. Genes Dev 2007; 21: 1443-55.

78. Trayhurn P, Wang B \& Wood IS. Hypoxia in adipose tissue: a basis for the dysregulation of tissue function in obesity? $\mathrm{Br}$ J Nutr 2008; 100: 227-35.

79. Rosen ED, Spiegelman BM. Molecular regulation of adipogenesis. Annu Rev Cell Dev Biol 2000; 16: 145-71.

80. Rangwala SM, LazarMA. Transcriptional control of adipogenesis. Annu Rev Nutr 2000; 20: 535-59.

81. Ntambi JM, Young-Cheul K. Adipocyte differentiation and gene expression. J Nutr 2000; 130: 3122S-6S

82. Pang C, Gao Z, Yin J, Zhang J, Jia W \& Ye J. Macrophage infiltration into adipose tissue may promote angiogenesis for adipose tissue remodeling in obesity. Am J Physiol Endocrinol Metab 2008; 295: E313-E22.

83. Ye J, Gao Z, Yin J \& He Q. Hypoxia is a potential risk factor for chronic inflammation and adiponectin reduction in adipose tissue of obob and dietary obese mice. Am J Physiol Endocrinol Metab 2007; 293: E1118-E28.

84. Lin Q, Lee YJ, Yun Z. Differentiation arrest by hypoxia. J Biol Chem 2007; 281: 30678-83.

85. Yun Z, Maecker HL, Johnson RS, Giaccia AJ. Inhibition of PPAR gamma 2 gene expression by the HIF-1-regulated gene DECV Stra13: a mechanism for regulation of adipogenesis by hypoxia. Dev Cell 2002; $2: 331-41$.

86. Takanabe R, Ono K, Abe Y, Takaya T, Horie T, Wada H, et al. Upregulated expression of microRNA-143 in association with obesity in adipose tissue of mice fed high-fat diet. Biochem Biophys Res Commun 2008; 376: 728-32.

87. Klöting $N$, Berthold $S$, Kovacs $P$, Schön MR, Fasshauer M, Ruschke $\mathrm{K}$, et al. MicroRNA expression in human omenta and subcutaneous adipose tissue. PLoS ONE 2009; 4: e4699.

88. Wang Q, Li YC, Wang J, Kong J, QiY, Quigg RJ, Li X. MiR-17-92 cluster accelerates adipocyte differentiation by negatively regulating tumor-suppressor Rb2/p130. Proc Natl Acad Sci U S A 2008; 105: 2889-94.

89. Xie H, Lim B, Lodish HF. MicroRNAs induced during adipogenesis that accelerate fat cell development are down regulated in obesity. Diabetes 2009; 58: 1050-7.

90. Schäffler A, Müller-Ladner U, Schölmerich J, Büchler C. Role of adipose tissue as an inflammatory organ in human diseases. Endocr Rev 2006; 27: 449-67.

91. Schwartz MW, Porte D, Jr. Diabetes obesity and the brain. Science 2005; 307: 375-9.

92. Mayr B, Montminy M. Transcriptional regulation by the phosphorylation-dependent factor CREB. Nat Rev Mol Cell Biol 2001; 2: 599-609.

93. Cao L, Lin EJ, Cahill MC, Wang C, Liu X, During MJ. Molecular therapy of obesity and diabetes by a physiological autoregulatory approach. Nat Med 2009; 15: 447-54.

94. Han JC, Liu QR, Jones M, Levinn RL, Menzie CM, JeffersonGeorge KS, et al. Brain-derived neurotrophic factor and obesity in theWAGRsyndrome. N Engl J Med 2008; 359: 918-27.

95. Weir GC, Bonner-Weir S. Five stages of evolving beta-cell dysfunction during progression to diabetes. Diabetes 2004; 53 Suppl 3: S16-S21.

96. Tillmar, L., Carlsson, C. \& Welsh, N. Control of insulin mRNA stability in rat pancreatic islets. Regulatory role of a $3^{\prime}-$ untranslated region pyrimidine-rich sequence. J. Biol. Chem. 2002; 277: 1099-106.

97. Knoch KP, Bergert H, Borgonovo B, Saeger HD, Altkrüger A, Verkade $\mathrm{P}$, et al. Polypyrimidine tract-binding protein promotes insulin secretory granule biogenesis. Nat. Cell Biol. 2004; 6: 207-14

98. El Ouaamari A, Baroukh N, Martens GA, Lebrun P, Pipeleers D, van Obberghen E. MiR-375 targets 3'phosphoinositidedependent protein kinase-1 and regulates glucose-induced biological responses in pancreatic betacells. Diabetes 2008; $57:$ 2708-17.

99. Du T, Zamore PD. microPrimer: the biogenesis and function of microRNA. Development. 2005; 132: 4645-52.

100. Esau C, Kang X, Peralta E, Hanson E, Marcusson EG, Ravichandran LV, et al. MicroRNA-143 regulates adipocyte differentiation. J Biol Chem 2004; 279: 52361-5.

101. Teleman AA, Maitra S, Cohen SM. Drosophila lacking microRNA miR-278 are defective in energy homeostasis. Genes Dev 2006; 20: 417-22.

102. Shi B, Sepp-Lorenzino L, Prisco M, Linsley $P$, deAngelis $T$, Baserga R. Micro RNA 145 targets the insulin receptor substrate-1 and inhibits the growth of colon cancer cells. J Biol Chem 2007; 282: 32582-90.

103. Kloosterman WP, Lagendijk AK, Ketting RF, Moulton JD, Plasterk RH. Targeted inhibition of miRNA maturation with morpholinos reveals a role for miR-375 in pancreatic islet development. PLoS Biol 2007; 5: e203.

104. Baroukh N, Ravier MA, Loder MK, Hill EV, Bounacer A, Scharfmann $\mathrm{R}$, et al. MicroRNA-124a regulates Foxa2 expression and intracellular signaling in pancreatic betacell lines. J Biol Chem 2007; 282: 19575-88.

105. Ippel JH, de Haas CJ, Bunschoten A, van Strijp JA, Kruijtzer JA, Liskamp RM, et al. MicroRNA miR-133 represses HERG $\mathrm{K}+$ channel expression contributing to QT prolongation in diabetic hearts. J Biol Chem 2007; 282: 12363-7.

106. Kato M, Zhang J, Wang M, Lanting L, Yuan H, Rossi JJ, et al. MicroRNA-192 in diabetic kidney glomeruli and its function in TGF-beta-induced collagen expression via inhibition of E-box repressors. Proc Natl Acad Sci U S A 2007; 104: 3432-7.

107. Carè A, Catalucci D, Felicetti F, Bonci D, Addario A, Gallo P, et al. MicroRNA-133 controls cardiac hypertrophy. Nat Med 2007; 13: 613-8.

108. Collins KK, Van Hare GF. Advances in congenital long QT syndrome. Curr Opin Pediatr 2006; 18: 497-502.

109. Paulussen A, Yang P, Pangalos M, Verhasselt P, Marrannes R, 
Verfaille $\mathrm{C}$, et al. Analysis of the human KCNH2(HERG) gene: identification and characterization of a novel mutation Y667X associated with long QT syndrome and a nonpathological 9 bp insertion. Hum Mutat 2000; 15: 483.

110. Kao DP, Witteles RM, Quon A, Wu JC, Gambhir SS, et al. Alterations in potassium channel gene expression in atria of patients with persistent and paroxysmal atrial fibrillation: differential regulation of protein and mRNA levels for $\mathrm{K}+$ channels. J Am Coll Cardiol 2001; 37: 926-32.

111. Zampetaki A, Kiechl S, Drozdov I, Willeit P, Mayr U, Prokopi $\mathrm{M}$, et al. Plasma microRNA profiling reveals loss of endothelial Mir-126 and other microRNAs in type 2 diabetes. Circ Res 2010; 107: 820-17.

112. Nathan DM. Long-term complications of diabetes mellitus. $\mathrm{N}$ Engl J Med. 1993; 328: 1676-1685.

113. Zampetaki A, Kiechl S, Drozdov I, Willeit P, Mayr U, Prokopi M, et al. Von Willebrand factor, type 2 diabetes mellitus, and risk of cardiovascular disease: the Framingham offspring study. Circulation. 2008; 118: 2533-9.

114. Wang S, Aurora AB, Johnson BA, Qi X, McAnally J, Hill JA, et al. The endothelial-specific microRNA miR-126 governs vascular integrity and angiogenesis. Dev Cell. 2008; 15: 261-71.

115. Fish JE, Santoro MM, Morton SU, Yu S, Yeh RF, Wythe JD, et al. miR-126 regulates angiogenic signaling and vascular integrity. Dev Cell. 2008; 15: 272-284.

116. VanWijk MJ, VanBavel E, Sturk A, Nieuwland R. Microparticles in cardiovascular diseases. Cardiovasc Res. 2003; 59: 277-87.

117. Zernecke A, Bidzhekov $K$, Noels $H$, Shagdarsuren $E$, Gan L, Denecke B, et al. Delivery of microRNA-126 by apoptotic bodies induces $\mathrm{CXCL} 12$-dependent vascular protection. Sci Signal. 2009; 2: ra81.
118. Prokopi M, Pula G, Mayr U, Devue C, Gallagher J, Xiao Q, et al. Proteomic analysis reveals presence of platelet microparticles in endothelial progenitor cell cultures. Blood. 2009; 114: 723-32.

119. Petri A, Lindow M, Kauppinen S. MicroRNA silencing in primates: towards the development of novel therapeutics. Cancer Res 2009; 69: 393-5.

120. Chen $\mathrm{X}, \mathrm{Ba} \mathrm{Y}, \mathrm{Ma} \mathrm{L}$, et al. Characterization of microRNAs in serum: a novel class of biomarkers for diagnosis of cancer and other diseases. Cell Res 2008; 18: 997-1006.

121. Chang TC, Mendell JT. MicroRNAs in vertebrate physiology and human disease. Annu Rev Genomics Hum Genet 2007; 8: 215-39.

122. Kolfschoten IGM, Roggli E, Nesca V, Regazzi R. Role and therapeutic potential of microRNAs in diabetes. Diabetes Obes Metab 2001; 11 (Suppl 4): 118-29.

123. Kajimoto $K$, Naraba $H$, Iwai N. MicroRNA and 3T3-L1 preadipocyte differentiation. RNA 2006; 12: 1626-32.

124. Chen JF, Mandel EM, Thomson JM et al. The role of microRNA-1 and microRNA-133 in skeletal muscle proliferation and differentiation. Nat Genet 2006; 38: 228-33.

125. Elmen J, Lindow M, Silahtaroglu $A$, et al. Antagonism of microRNA-122 in mice by systemically administered LNAantimiR leads to up-regulation of a large set of predicted target mRNAs in the liver. Nucleic Acids Res 2008; 36 : $1153-62$.

126. Ebert MS, Neilson JR, Sharp PA. MicroRNAsponges: competitive inhibitors of small RNAs in mammalian cells. Nat Methods 2007; 4: 721-26.

127. Volinia S, Calin GA, Liu CG et al. A microRNA expression signature of human solid tumors defines cancer gene targets. Proc Natl Acad Sci USA 2006; 103: 2257-61. 